Original Research

\title{
Deflection of a Concrete T-beam with Prestressed and Non-prestressed Fiber Reinforcement Polymers at Elevated Temperatures
}

Mohammed Faruqi * Zachary Scott Dean, Francisco Aguiniga, Breanna Bailey

Department of Civil and Architectural Engineering, MSC 194, Texas A\&M-Kingsville, Kingsville, TX 78363, USA; E-Mails: $\quad$ m-faruqi@tamuk.edu; zachary.dean@students.tamuk.edu; francisco.aguiniga@tamuk.edu; breanna.bailey@tamuk.edu

* Correspondence: Mohammed Faruqi; E-Mail: $\underline{\text { m-faruqi@tamuk.edu }}$

Academic Editor: Luciano Ombres

Special Issue: Fiber Composite Materials and Civil Engineering Applications

Recent Progress in Materials

2021, volume 3 , issue 1

doi:10.21926/rpm.2101002
Received: November 15, 2020

Accepted: January 06, 2021

Published: January 15, 2021

\begin{abstract}
Prestressed concrete members have gained popularity as an efficient and effective way of designing a structural member with the best engineering and material properties. The method of prestressing a structural concrete member has the capability of controlling increased service loads with less depth over longer spans. However, deflections from over-loading or loading over time give a disadvantage to the common steel reinforced concrete members by the effect of corrosion as the structural concrete develop cracks. To prevent corrosion of a structural concrete member, exchanging of steel reinforcement with Fiber Reinforcing Polymers (FRP) has sparked engineering interest in recent years. Both prestressed and non-prestressed FRP reinforcement can reduce tension in concrete. However, the performance of such structural members under elevated temperatures is currently unknown. The knowledge and application of this may lead to a cost effective, and practical consideration in fire safety design. In this article, an analytical model is developed using flexural rigidity of a concrete T-beam with both prestressed and non-prestressed
\end{abstract}

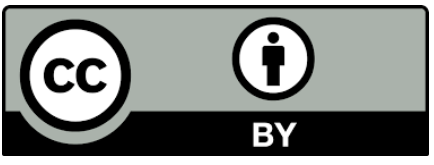

(C) 2021 by the author. This is an open access article distributed under the conditions of the Creative Commons by Attribution License, which permits unrestricted use, distribution, and reproduction in any medium or format, provided the original work is correctly cited. 
FRP reinforcement to study the deflection behavior at practical elevated temperatures. The model is compared with the finite element model (FEM) of a T-beam with both prestressed and nonprestressed reinforcement subjected to practical elevated temperatures. In addition, comparison is also made with an indirect reference to the real behavior of the material. The results of the analytical model correlated reasonably with the FEM and the real behavior, and were within the accepted range of the American Concrete Institute ( $\mathrm{ACl}$ ) specifications.

\section{Keywords}

FRP; concrete; elevated temperatures; deflections; prestress; non-prestressed

\section{Introduction}

Fiber Reinforcing Polymers (FRP) have exceptional performance in environments in which exposure leads to corrosion. Eliminating and controlling corrosion of the reinforcement in a structural concrete member increases the life serviceability and structural integrity of the member. FRP reinforcement has the ability to maintain it homogeneous properties over time. This means that a structural member will have the same engineering properties years later just as it was at initial service. Another method of improving the performance of a structural member is eliminating tension in the concrete by the application of prestressing and non- prestressed FRP reinforcement. FRP tendons for prestressing applications are emerging as one of the most promising technologies in the civil engineering industry [1]. Therefore, the combined technique of using FRP reinforcement and reducing tension in a concrete structural member will result in increased serviceability and durability over time.

FRPs are high-performance materials and offer a wide range of applications [1]. However, when used in building applications, they need to conform to fire resistance rating stated in the building codes [1]. When exposed to fire, FRP materials may suffer charring, melting, delamination, cracking and deformation [2]. The epoxy resin in FRP loses stiffness and becomes soft when subjected to elevated temperatures that exceed the glass transition temperature $\left(T_{g}\right)$. The glass transition region is the most significant practical region of FRP for design purposes. This is because the system undergoes significant plastic deformations beyond the region resulting in structural collapse.

The polymer has significant changes in the ability to resist deformation and this has a direct correlation to the material's modulus of elasticity. Without protection from heat, a polymer matrix may also ignite, emit smoke, and support flame spread [2]. The polymer matrix supports and protects the fibers, transfers and distributes forces to the fibers, and disperses and maintains the spacing of the fibers [2]. It is fair to say that FRP experiences mechanical changes that can cause an increase in crack width and greater deflections at elevated temperatures. Therefore, deterioration of mechanical properties of FRP with increasing temperature, along with associated changes in member behavior, are important considerations [3].

Hawileeh et al. [4] modeled and studied a finite element model of a T-beam reinforced with steel rebars and strengthened with insulated Carbon Fiber Reinforced Polymers (CFRPs) sheet exposed to 
fire. Good agreement was found between the model and the measured results. Naser et al. [5] studied T-beams exposed to fire, that were strengthened using CFRPs plates insulated with various materials. Strong correlation between the predicted, experimental, and finite element results was found. Hawileeh [6] performed thermal stress finite element analysis of CFRP strengthened concrete beam exposed to top surface fire to study the heat transfer mechanism within the strengthened beam. It was found that heating the top surface minimizes the deflection at the mid-span.

There are hardly any studies that have examined a structural concrete beam with pure CFRPs reinforcement of both prestressed and non-prestressed reinforcement, and even less is known about the impact of elevated temperatures. Deflection is defined as a characteristic of evaluating structural serviceability of a FRP reinforced concrete member [7]. Therefore, this basic work examines the deflection effects of a pure carbon FRP reinforcement with both prestressed and non-prestressed reinforcement in a T-beam at elevated temperatures.

\section{Proposed Approach}

\subsection{Formulation of the Flexural Rigidity $(E I)_{\Delta T}$}

The effective flexural rigidity of the composite member at elevated temperatures is carefully develop-ped by a modulus of elasticity relationship in the reinforcement and concrete. The reason for the use of this relationship is to establish a single material moment of inertia for the structure.

At elevated temperatures, each material in a composite member experiences a different reduction in strength, depending on the temperature loading to the structure. This proposed approach examines and incorporates the strength reductions into the flexural rigidity to determine deflection. The effective flexural rigidity of the composite member at elevated temperatures is determined by the following assumptions:

- The fiber composite was assumed to be unidirectional and the fibers to be continuous and parallel [1]. Modulus of elasticity is uniform in the longitudinal direction of the tension reinforcement at zero temperature strains.

- Perfect contact exists between carbon fibers and matrix. Delamination shall not occur with the contact between the tension reinforcement and concrete.

- Strains experienced by the fibers, matrix and concrete are approximately equal [8].

- The strain diagram is linear for concrete members reinforced with FRP reinforcement.

- The normal stress in the non-prestressed and prestressed FRP is equal and in opposite direction after decompression (prestressing application).

An approximation of the flexural rigidity for a concrete a T-beam with prestressed and nonprestressed fiber reinforcement polymers at glass transition temperatures $\left(T_{g}\right)$ is shown in equation (1), where $\left(E_{c @ \Delta T}\right)$ is the temperature based modulus of elasticity of the concrete, and $\left(I_{e @ \Delta T}\right)$ is the temperature based effective moment of inertia of the structural composite member. The $\left(E_{c @ \Delta T}\right)$ can be calculated using equation (2).

$$
(E I)_{\Delta T}=E_{c @ \Delta T} I_{e @ \Delta T}
$$




$$
E_{c @ \Delta T}=r E_{c}
$$

The variable $(r)$ is a strength reduction factor that is based on the concrete behavior at elevated temperatures. This reduction of elastic modulus with varying temperatures has been reported [9-13] and its application has been shown [1]. The modulus of elasticity of the concrete $\left(E_{c}\right)$, is $E_{c}=4730 \sqrt{f_{c}^{\prime}}$ where $f_{c}{ }^{\prime}$ is the 28-day compressive strength of the concrete. Next, the temperature based effective moment of inertia $\left(I_{e @ \Delta T}\right)$, is a function of the gross moment of inertia $\left(I_{g}\right)$, and the cracked cross section of the moment of inertia (transformed moment of inertia) $\left(I_{c r}\right)_{\Delta T}$ Each of these moments of inertia has a different location for the neutral axis and controls the temperature strain for the FRP tension reinforcement in the structure. The effective moment of inertia is also a function of the cracking moment $\left(M_{c r}\right)_{\Delta T}$ and action moment $\left(M_{a}\right)$. This is shown in equation (3).

$$
I_{e @ \Delta T}=\left[\frac{\left(M_{c r}\right)_{\Delta T}}{M_{a}}\right]^{3} I_{g}+\left[1-\left[\frac{\left(M_{c r}\right)_{\Delta T}}{M_{a}}\right]^{3}\right]\left(I_{c r}\right)_{\Delta T}
$$

The transformed cross section $\left(I_{c r}\right)_{\Delta T}$ of the structure converts the material to one material by converting the FRP reinforcement to concrete. Equation (4), shows the temperature based modular

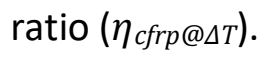

$$
\eta_{c f r p @ \Delta T}=\frac{E_{C F R P @ \Delta T}}{E_{c @ \Delta T}}
$$

Where, $\left(E_{C F R P @ \triangle T}\right)$ is developed by the rule of mixtures for the FRP reinforcement. It is known that the elastic modulus of the fibers is not affected in the glass transition zone of the matrix [14]. This is because the fibers have a higher glass transition temperature then the matrix. Accordingly, each elastic modulus is multiplied by their respective volume fractions and added together. The combined modulus is shown in equation (5).

$$
E_{C F R P @ \Delta T}=E_{m @ \Delta T} V_{m}+E_{f} V_{f}
$$

\subsection{Validation}

Equations (1) to (5) will later be used in the application and comparison of results section for validation with the finite element analysis of a simply supported concrete T-beam with both prestressed and non-prestressed FRP reinforcement to study the deflection behavior at elevated temperatures.

\section{FEM and Model Description}

The failure of reinforced concrete structures, such as prestressed beams, under increasingly monotonic static loading conditions are of interest to us. These failures have been studied using discrete crack models [15-18] among many. Most of these approaches have the disadvantage of being computationally expensive and in one of the approaches [19], the failure is dependent on the geometry and the topology of the mesh. Remeshing and refinement can overcome this challenge; however, these 
computations are also expensive. Mesh free methods have been proposed [20-24]. However, mesh free methods also tend to be computationally more expensive than FEM. Therefore, in view of our financial constraints, a very simple first approach was under taken here. This can later be used by other researchers to advance the knowledge. In addition, the following basic guidelines were used for the FEM beam models: a) define constants, b) material properties, c) establish the FE mesh, element numbers, and nodes, d) define real loading, boundary conditions, and constraints, and e) identify the unknown quantities.

Furthermore, modeling a reinforced concrete structure to produce an effective FEM model relies on the knowledge and understanding of computations that the software will use to execute the simulation. For reinforced concrete structures, not only cracking of concrete plays a significant role, but also the interaction between concrete and the reinforcement [24]. One of the most significant attributes of modeling a structure using the FEM modeling method is the understanding of how the bond will be maintained between the concrete and FRP. In this model, temperature loading is represented in the form of temperature strains and thermal expansion of the material. With an assumption that perfect bond is still maintained in the structure. Using the concrete constitutive model together with the bond model, the complicated behavior of a structure can be studied [24].

For our structure, the FEM model was solved by Ansys Workbench 17.2 for multiple elevated temperature simulations with the import of the geometry and assembly of the member from SolidWorks 16.0. The structure was designed to the geometry that is common to the civil engineering industry of a T-shape with tension reinforcement. The T-shaped cross section is more efficient, have a large moment of inertia compared to a rectangular cross section.

Figure 1 shows the loading of our structure. The loading is symmetric with respect to the mid-point length of the beam under simple support conditions. The uniform distributed load to the structure was based on the ASCE code [25] and consisted of a dead load of $3.25 \mathrm{kN} / \mathrm{m}$ and live load of $2.87 \mathrm{kN} / \mathrm{m}$. A third point loading condition of $500 \mathrm{kN}$ for the structural system was used to control the deflection in the member. This third point condition was to avoid the elongation due to temperature strains from expanding past the roller support condition.

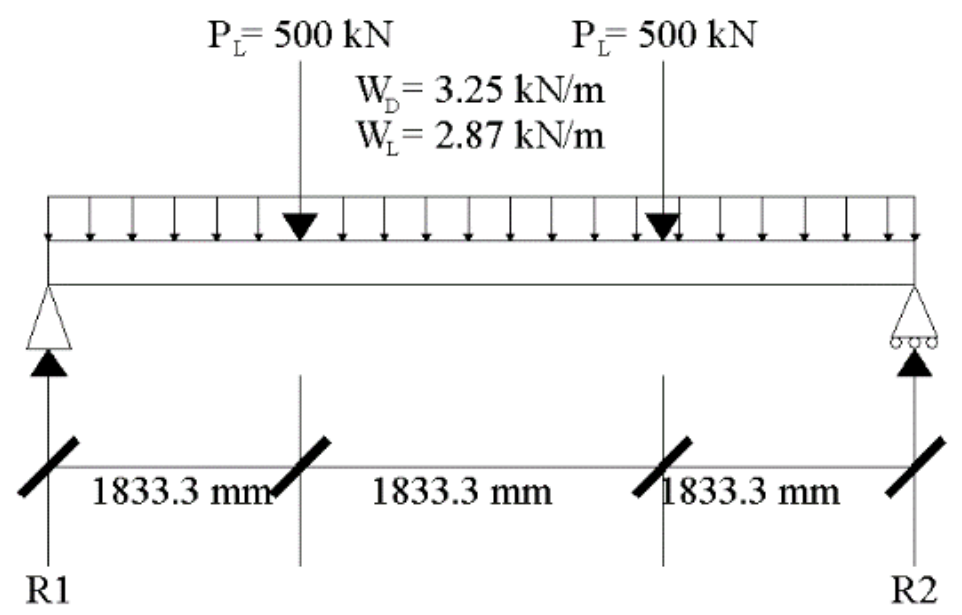

Figure 1 Loading of the structure. 


\subsection{Modeling Using SolidWorks 16.0}

The beam was configured in SolidWorks 16.0 with metric units to develop the T-shape of the structure. Then, the cross section was extruded to create the length of the beam of 5.5 meters. Next, the non-prestressed reinforcement was established was established by extruding the six holes in the bottom of the beam. A hole was then created for the prestressed reinforcement with the sweep feature of the software. Finally, a model of the tension reinforcement was created for the assembly of the complete structure in the SolidWorks model. Cross section for the mid-span and end-span are displayed in Figure 2.
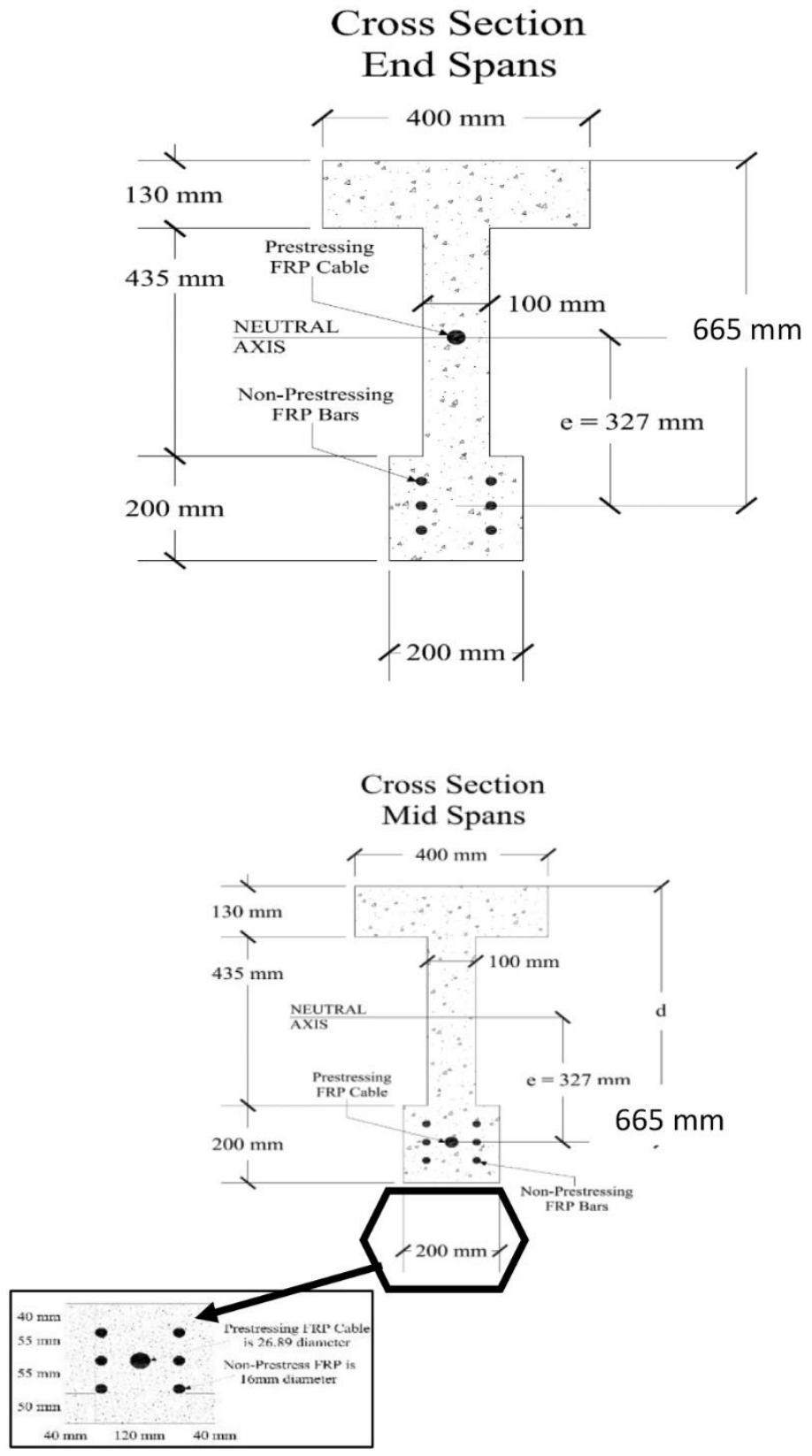

Figure 2 Concrete cross section of a T-beam with FRP reinforcement location. 
Composite material selected for the tension reinforcement of the structure was Carbon Fiber Reinforcing Polymer (CFRP). The non-prestressed reinforcement was $6-\mathrm{C} 2$ rebars with a diameter of $16 \mathrm{~mm}$. Prestressed tension reinforcement had a diameter of $26.89 \mathrm{~mm}$. The concrete cover was 50 $\mathrm{mm}$ for the non-prestressed reinforcement, and at midspan the prestressed reinforcement had 105 $\mathrm{mm}$ of concrete cover. Note that for this structural system the prestressed reinforcement was modeled as one area. Referencing from the bottom extreme concrete fiber the distance to the neutral axis is 427 $\mathrm{mm}$. The beam depth was $765 \mathrm{~mm}$ with the depth of the reinforcement at $665 \mathrm{~mm}$. The design of the structure was to model a FRP reinforced T-beam that would reflect a good result from the temperature based deflection. The effective prestress force was determined by checking stresses in the concrete for a flexural member [26]. The critical stresses for this structure were at the midspan, and not to exceed commonly used $35 \mathrm{MPa}$ compressive stress of the concrete. The compressive stress was based on service load conditions, and calculated by the following equation:

$$
f_{1}=-\frac{P_{e}}{A_{C}}\left(1-\frac{e c_{1}}{r_{g}^{2}}\right)-\frac{M_{T}}{S_{1}}
$$

Where, $P_{e}$ is the effective prestress force, $A_{c}$ is cross section area, $e$ is the eccentricity, $c_{1}$ is the depth of the compression, $r_{g}^{2}$ is the radius of gyration, $M_{T}$ is the total moment, and $S_{1}$ is the compression section modulus.

Therefore,

$$
\begin{gathered}
f_{1}=-\frac{(120)\left(10^{3}\right)}{135500}\left(1-\frac{(327)(332.81)}{(66.756)\left(10^{3}\right)}\right)-\frac{(900.57)(1000)(1000)}{(27.17)\left(10^{6}\right)} \\
=-32.58 \mathrm{MPa}<35 \mathrm{MPa}
\end{gathered}
$$

For this compressive stress evaluation, the effective prestress force was developed to not overreinforce the structure. Whereas a large prestress force might cause the beam to have an increase in stiffness. Commonly used prestressing to the system was $150 \mathrm{kN}$ for the initial prestressing force. Therefore, the effective prestressing force from the industry standard was taken as $80 \%$ of initial prestressing. The beam had a max eccentricity at midspan of $327 \mathrm{~mm}$, and to eliminate eccentricity at the end span the effective prestress force was applied at the neutral axis. A parabolic reinforcement profile was established with the prestressing force applied at $16^{\circ}$. This angle allowed the prestress force to be directly in line with the CFRP tendon at the end spans. The eccentricity varied throughout the profile of the T-shaped cross section. The reinforcement profile for the T-beam as well as the effective prestressing force is illustrated in Figure 3. 


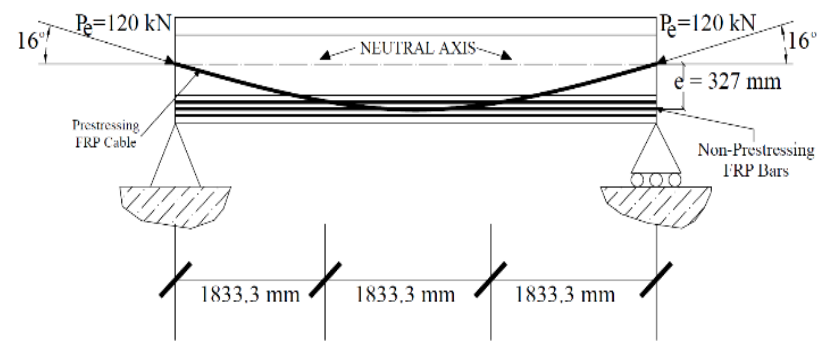

Figure 3 Reinforcement profile of the FRP reinforced concrete T- beam structure.

\section{ANSYS Workbench FEM Modeling}

The structure was imported into ANSYS 17.2 and the engineering data was assigned to the structure. Table 1 [5] shows the engineering data. For practical design purposes, in this initial study, material properties were approximated at elevated temperatures, based on the suggestion of open literature $[3,9]$. The import of the geometry is shown in Figure 4.

Table 1 Material properties.

\begin{tabular}{lll}
\hline Material Properties & Concrete & CFRP \\
\hline $\begin{array}{l}\text { Young's Modulus } \\
\left(\mathrm{kN} / \mathrm{mm}^{2}\right)\end{array}$ & 27.9 & 396 \\
$\begin{array}{l}\text { Poisson's Ratio }(\mathrm{v}) \\
\text { Coefficient of Thermal }\end{array}$ & 0.18 & 0.27 \\
Expansion $\left(\mathrm{C}^{-1}\right)$ & $1.4 \times 10^{-5}$ & $3.0 \times 10^{-5}$ \\
& 2300 & 1540 \\
\hline
\end{tabular}




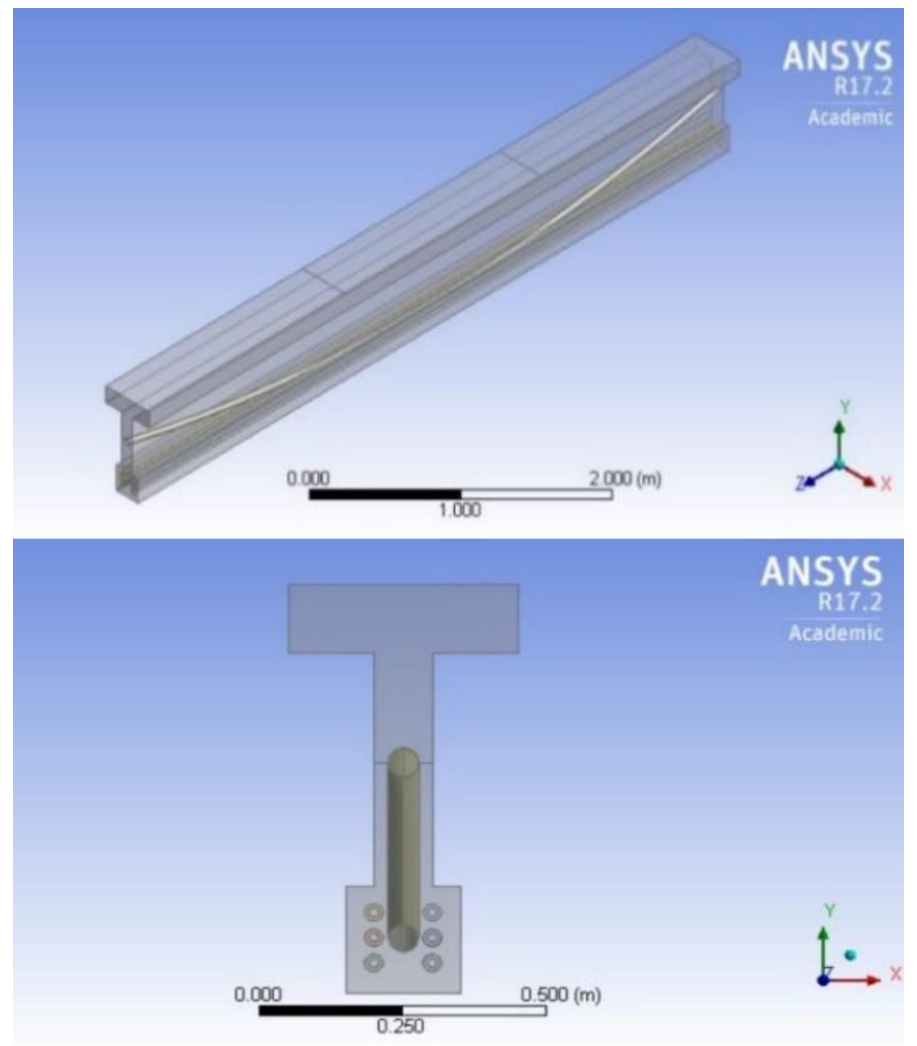

Figure 4 Geometry import into Ansys 17.2.

To develop the finite element model, the software was configured to several settings in a static structure application that would produce the results needed for this study. First, the structural system was set up to bond the reinforcement to concrete. Second, support conditions for a simply supported structure were positioned at each end of the beam. At the bottom edge of the beam, a pin connection was modeled by fixing that edge and allowing for rotation about the X-axis of the structure. At the other bottom edge of the beam, a roller connection was modeled using the displacement setting. Displacements at that edge was configured to only allow displacement in the Z-axis.

The other axes were set to zero. This was to control displacement in the X or Y-Axis of the system. Before, inserting forces to the structure a new coordinate system was established from the global coordinate system to allow for the prestressing force to be applied. This new coordinate system had an origin at each end of the CFRP prestressing tendon/cable and was rotated from the global coordinate system by 16 degrees. Finally, forces were applied to the structure as shown in Figure 5 . The Figure 5 shows software configuring a mesh for the entire structural system. The meshing was limited in this study due to the academic use of this software. Meshing statistics for this structure include 8,963 elements and 16,173 nodes. The three-dimensional mesh was generated on the surface of the structure. A balance between accuracy and computing time was taken into account for our mesh size. Thermal SOLID70 element was converted to SOLID65 structural element for concrete material. Link33 element was converted to structural element LINK8 for CFRPs material. Thermal problems are generally nonlinear in nature. In this initial study, a default convergence criterion was used. The beam was structurally analyzed with simply supported end conditions. 


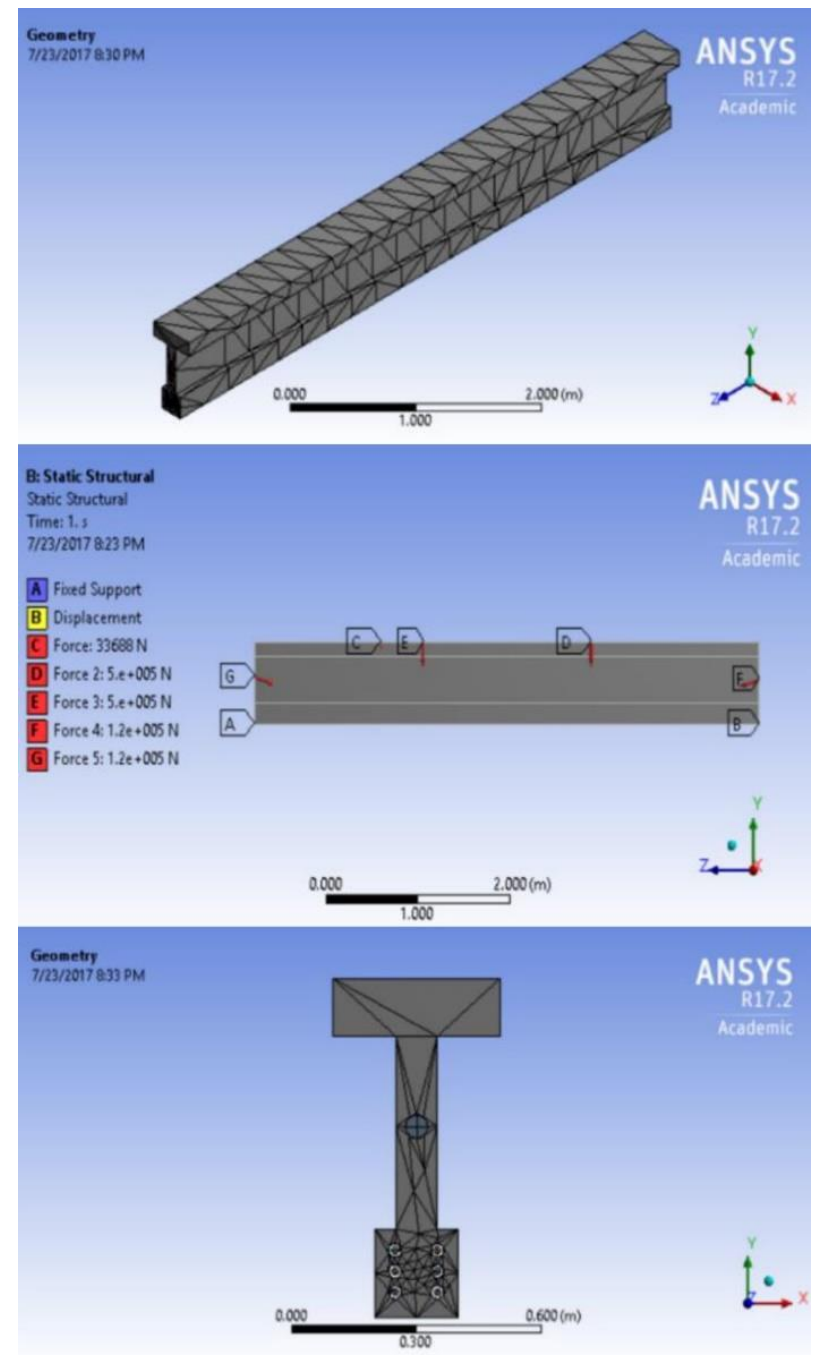

Figure 5 Forces and FEM meshing applied to the structure.

\section{FEM Analysis}

The epoxy-carbon FRP system is classified as a thermoset since the matrix for the FRP is developed from an epoxy. In the glass transition region of the temperature range, the epoxy matrix has a reduction in mechanical properties mostly influencing the effective elastic modulus of the FRP system [14]. The temperature range for this study was correspondent with the glass transition range of $150-200^{\circ} \mathrm{C}$. For design purposes, it is recommended, that maximum temperatures must be less than the glass transition zone [8]. Also, for design a control, temperature must be established, this is where, zero temperature strains can occur. In the FEM model, the temperature set for zero temperatures strain conditions was $22^{\circ} \mathrm{C}$.

With all load stages acting on the structure, the FEM model was solved for deflection in the $\mathrm{Y}$ direction. In order to evaluate worst practical scenario, a mid-range glass transition temperature of $175^{\circ} \mathrm{C}$ was applied to the entire structure. The structure yielded a deflection of $8.52 \mathrm{~mm}$. Figure 6 illustrates the simulation of the deflected structure. 


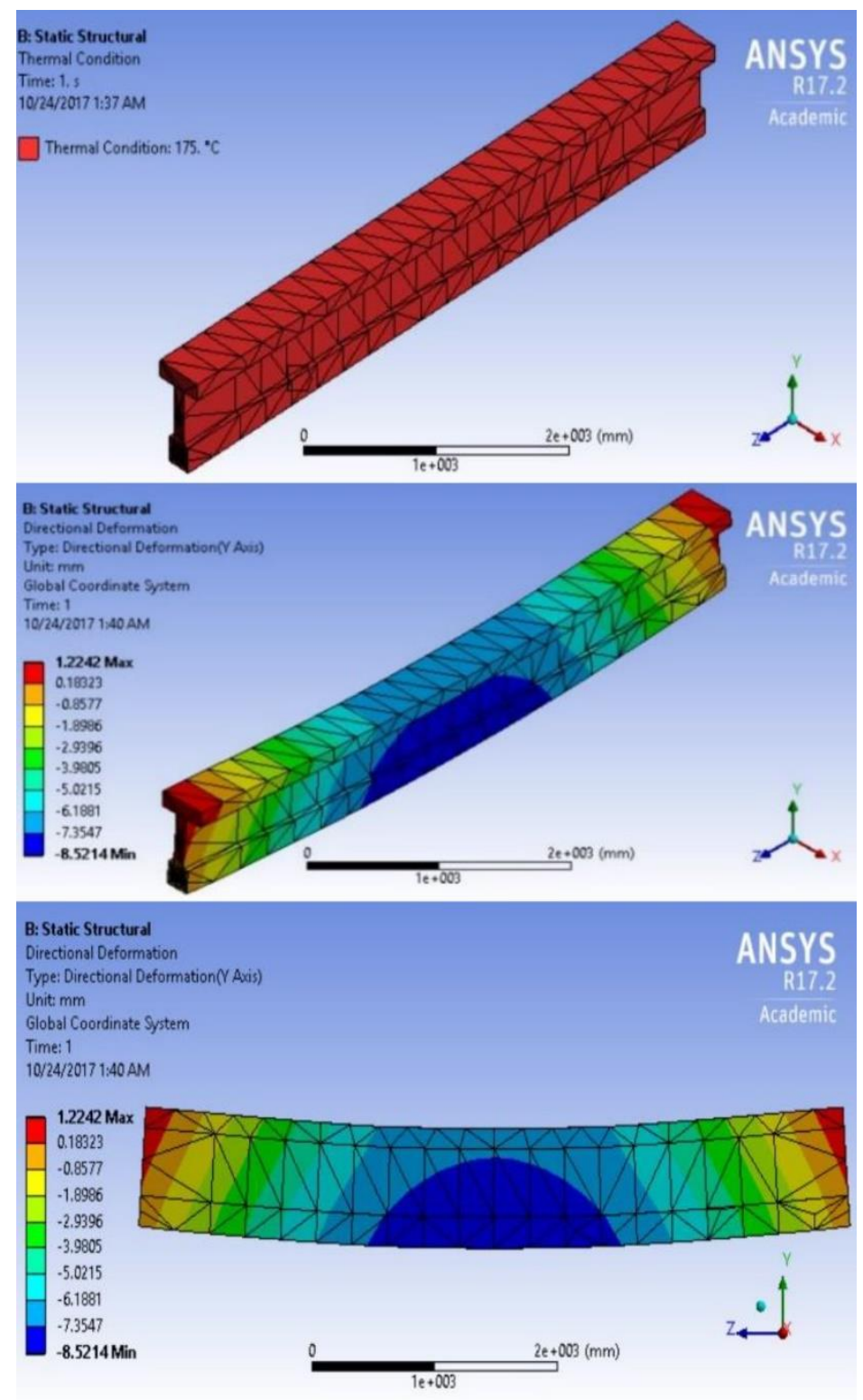

Figure 6 Deflected structural system.

\section{Application and Comparison of Results}

In order to determine the deflection behavior of a concrete T-beam subjected to structural and temperature loading the flexural rigidity must be established for the structure. The flexural rigidity is composed of a temperature based modulus of elasticity and moment of inertia. This flexural rigidity (EI) of the structure is reduced with the effects of temperature loading in the FRP. These considerations were developed earlier in equations (1) through (5).

For this application, the deflections are considered to have all load stages applied to the structure simultaneously. These loads are inclusive of all transverse loads and elevated temperature conditions. The moment of inertia is dependent on the amount of cracking that takes places in the member. Therefore, the neutral axis moves up decreasing the depth of the compression in the concrete. The 
member preforms as an under-reinforced member. When the concrete cracks, the tension carried by the concrete between the cracks will tend to stiffen the member [26]. However, at elevated temperature the FRP will elongate as the epoxy matrix loses stiffness.

In the glass transition region $\left(150-200^{\circ} \mathrm{C}\right)$ of the epoxy matrix the stiffness is reduced. However, this reduction in stiffness still allows for load transfer from fiber to fiber throughout the FRP tension reinforcement. An example with annotation to calculate the deflection of a concrete T-beam with prestressed and non-prestressed carbon fiber reinforcement polymers at elevated temperatures is presented in the following discussion:

A simply supported T-beam with a length of $5500 \mathrm{~mm}$ and a depth of $765 \mathrm{~mm}$ reinforced with CFRP tension reinforcement is used. The beam is loaded with two loads of $500 \mathrm{kN}$ offset $1833.3 \mathrm{~mm}$ from each support end of the beam. A uniform distributed dead load of $3.25 \mathrm{kN} / \mathrm{m}$ and live load of $2.87 \mathrm{kN} / \mathrm{m}$ is also acting on the beam. The CFRP tension reinforcement is made up of both prestressed and nonprestressed reinforcement.

For the non-prestressed reinforcement, six - C2 CFRP rebar are used and a CFRP cable in the shape of a parabola with a diameter of $26.89 \mathrm{~mm}$ is used for prestressed reinforcement. Figure 1 above shows the basic loading of the structure. All tension reinforcement is perfectly bonded to the concrete and fully braced. A commonly used fiber volume fraction of CFRP between $65-75 \%$ is used [15]. The modulus of elasticity of the matrix $\left(E_{\mathrm{m}}\right)$ and fibers $\left(\mathrm{E}_{\mathrm{f}}\right)$ are respectively $3.5 \mathrm{kN} / \mathrm{mm}^{2}$ and $550 \mathrm{kN} / \mathrm{mm}^{2}$. The elastic modulus of the CFRP is $396 \mathrm{kN} / \mathrm{mm}^{2}$ and strength of the concrete, $f_{c}^{\prime}=35 \mathrm{kN} / \mathrm{mm}^{2}$. The modulus of elasticity for the concrete is calculated as:

$$
E_{c}=4730 \sqrt{f_{c}^{\prime}}=4730 \sqrt{35}=27.9 \mathrm{kN} / \mathrm{mm}^{2}
$$

First, the effective moment of inertia $\left(I_{e @ \Delta T}\right)$ is established based on the function of the gross moment of inertia of the cross section $\left(I_{g}\right)$, and the cracked moment of inertia $\left(I_{c r}\right)_{\Delta T}$. Each of these moment of inertia controls the temperature behavior of the FRP tension reinforcement in the T-beam structure. The effective moment of inertia is also a function of the cracking moment $\left(M_{c r}\right)_{\Delta T}$ and action moment $\left(M_{a}\right)$. This is calculated using equation (3). Where, the limit for the effective moment of inertia is between the gross moment of inertia and the cracked moment of inertia as noted in the American Concrete Institute Code [27],

$$
I_{g}>I_{e}>I_{c r}
$$

We can use superposition of the structure to determine the maximum action moment $\left(M_{a}\right)$ at the mid-span of the structure.

$$
\begin{aligned}
& M_{a}=-P_{e} e+\frac{\left(W_{D}+W_{L}\right) \ell^{2}}{8}+\frac{P_{L} \ell}{3} \\
& =-(120)(.327)+\frac{(6.12)(5.5)^{2}}{8}+
\end{aligned}
$$




$$
\begin{aligned}
& \frac{(500)(5.5)}{3} \\
M_{a}= & 900.57 \mathrm{kN}-\mathrm{m}
\end{aligned}
$$

A $2 \%$ reduction in the compressive strength of the concrete generally achieves a temperature based cracking moment for the structure [26]. This reduction in compressive strength is for temperatures less than $200^{\circ} \mathrm{C}$ [26]. We can then establish the temperature based modulus of rupture $\left(f_{r}\right)$. Then, $\left(f_{r}\right)=$ $0.7 \sqrt{\left(.98 f_{c}^{\prime \prime}\right)}=0.7[0.98 * 35]^{0.5}=4.10 \mathrm{~N} / \mathrm{mm}^{2}$. This temperature based modulus of rupture will account for the moment, when the tension in the concrete causes the development of cracks on the tension side $\left(y_{t}\right)$ of the structure. The cracking moment $\left(M_{c r}\right)_{\Delta T}$ is given by the equation:

$$
\left(\mathrm{M}_{\mathrm{cr}}\right)_{\Delta \mathrm{T}}=\frac{\mathrm{f}_{\mathrm{r}} \mathrm{I}_{\mathrm{g}}}{y_{\mathrm{t}}}
$$

The T-shape of the cross section requires the location of the centroid to determine the distance from the neutral axis to extreme tension fiber of the cross section. Taking the bottom of the cross section shown in Figure 7 as reference for calculations, we have:

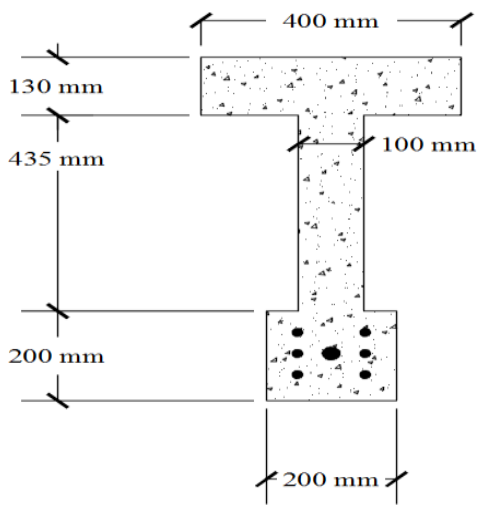

Figure 7 Gross cross section of the concrete T-beam at mid-span.

$$
\begin{gathered}
y_{t}=\frac{\Sigma\left(y^{\prime} A\right)}{\Sigma A} \\
y_{t}=\frac{4,000,000+18,161,250+36,400,000}{40000+43500+52000} \\
y_{t}=432.16 \mathrm{~mm}
\end{gathered}
$$

For the gross moment of inertia $\left(I_{g}\right)$, the application of the parallel axis theorem about the centroid will be applied using the equation:

$$
I_{g}=\Sigma\left(I_{0}+A d^{2}\right)
$$

Where, $\left(I_{0}\right)$ is the moment of inertia with respect to this axis, $(A)$ is the area with respect to the neutral 
axis, and $(d)$ is the distance from the local centroid of the area to the neutral axis. Therefore,

$$
\begin{gathered}
\frac{1}{12}(200)\left(200^{3}\right)+(200)(200)(432.18-100)^{2} \\
+\frac{1}{12}(100)\left(435^{3}\right)+(100)(435)(432.1-417.5)^{2} \\
+\frac{1}{12}(400)\left(130^{3}\right)+(400)(130)(700-432.18)^{2} \\
I_{g}=9,045,456,461 \mathrm{~mm}^{4}
\end{gathered}
$$

Substituting the values for the modulus of rupture, gross area moment of inertia, and distance of the tension side of the T-beam $\left(y_{t}\right)$ into equation (7):

$$
\begin{aligned}
\left(M_{c r}\right)_{\Delta T} & =\frac{(4.10)(9045456461)}{432.16} \\
& =85.82 \mathrm{kN}-\mathrm{m}
\end{aligned}
$$

Next, the cracked moment of inertia is calculated for the section considering a temperature of $175^{\circ} \mathrm{C}$. The cracked section represents the concrete after tension stress have exceeded the modulus of rupture for the concrete. This calculation is dependent on the geometry of the transformed area of the cross section. The CFRP is converted to concrete with the use of the modular ratio in equation (4).

Generally, the stress-strain curve for concrete subjected to elevated temperatures exhibits a linear response followed by a parabolic response till peak stress, and then a quick descending portion to failure [11]. Accordingly, reduction in the relative elastic modulus of concrete also occurs at these temperatures $[12,13]$. There is less than $10 \%$ decrease in the modulus of elasticity of the concrete. This approximate decrease is for a temperature range of $0-200^{\circ} \mathrm{C}$. Using equation (2), the concrete modulus of elasticity is approximately reduced by $5 \%$ for a temperature of $175^{\circ} \mathrm{C}$. Therefore,

$$
\begin{gathered}
E_{c @ \Delta T}=r E_{c}=(.95)(27.9) \\
=26.5 \mathrm{kN} / \mathrm{mm}^{2}
\end{gathered}
$$

For the CFRP, it is known that the storage (elastic) modulus for the matrix is developed from a Dynamic Mechanical Analysis (DMA). Changes in the storage modulus behavior reflect changes in the polymer matrix and/or the fiber/matrix interface. This is because the carbon fiber modulus does not change in the temperature region studied [14]. At approximately $170-176^{\circ} \mathrm{C}$ range, the matrix fails to transfer loads between fibers [14]. The tensile strength of unidirectional composites depends strongly on the fiber-matrix adhesion and the ability of the matrix to transfer stresses from highly stressed fibers to other fibers [14]. Accordingly, only the reduction in the modulus of elasticity of the matrix is considered. Using equation (5), and the DMA analysis [14], the strength of the matrix is reduced by $42 \%$ of the original strength of $3.5 \mathrm{kN} / \mathrm{mm}^{2}$. 
Therefore,

$$
\begin{gathered}
E_{m @ \Delta T}=(.58)(3.5) 2.03 \mathrm{kN} / \mathrm{mm}^{2} ; \text { and } \\
E_{C F R P @ \Delta T}=E_{m @ \Delta T} V_{m}+E_{f} V_{f} \\
=(.28)(2.03)+(.72)(550)=396 \mathrm{kN} / \mathrm{mm}^{2}
\end{gathered}
$$

The temperature based modular ratio is determined by substituting the values for $E_{C F R P @ \Delta T}$ and $E_{c @ \Delta T}$ into equation (4).

Therefore,

$$
\eta_{c f r p @ \Delta T}=\frac{E_{C F R P @ \Delta T}}{E_{c @ \Delta T}}=\frac{396000}{26500}=14.94
$$

It is assumed that the neutral axis for the cracked cross section of the structure will be in the web and not in the compression flange as shown in Figure 8.

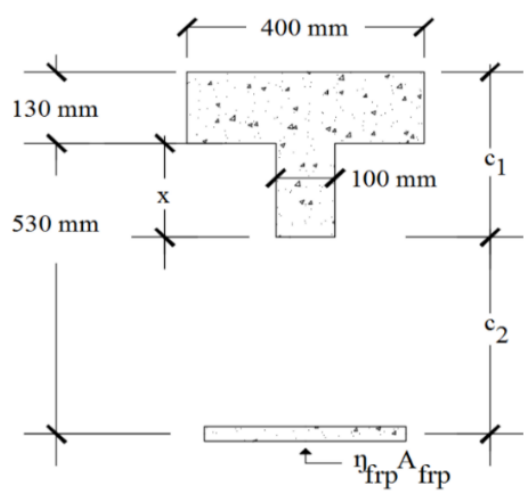

Figure 8 Cracked cross section of the concrete T-beam at mid-span.

The cracked moment of inertia $\left(I_{c r}\right)_{\Delta T}$ is determined by the application of the first moment of inertia. The tension side of the beam will be setting equal to the compression side of the cross section to find the location of the neutral axis at a distance $(x)$ away from the bottom of the compression flange. The total tension reinforcement area at mid-span is:

$$
A_{c f r p}=6\left(\frac{\pi}{4}(16)^{2}\right)+\frac{\pi}{4}(26.89)^{2}=1774.27 \mathrm{~mm}^{2}
$$

Therefore,

$$
\eta_{c f r p @ \Delta T} A_{c f r p}=26,507.59 \mathrm{~mm}^{2}
$$

Solving for the location of the neutral axis yields: 


$$
\begin{gathered}
(400)(130)\left(x+\frac{130}{2}\right)+(x)(100)\left(\frac{x}{2}\right)=26,507.59(660-(130+x)) \\
x=125.82 \mathrm{~mm}
\end{gathered}
$$

Total depth of compression region of the cross section from the top of the compression flange is $255.82 \mathrm{~mm}$, and the total depth of the tension from the centroid of the CFRP reinforcement to the neutral axis is $404.18 \mathrm{~mm}$.

The moment of inertia for the cracked section $\left(I_{c r}\right)_{\Delta T}$ can now be calculated as:

$$
\begin{gathered}
\frac{1}{12}(400)\left(130^{3}\right)+(400)(130)\left(125.82+\frac{130}{2}\right)^{2} \\
+\frac{1}{12}(100)\left(125.82^{3}\right)+(100)(125.82)\left(\frac{125.82}{2}\right)^{2} \\
+(26,507.59)(404.18)^{2}
\end{gathered}
$$

Therefore,

$$
\left(I_{c r}\right)_{\Delta T}=6,363,384,270 \mathrm{~mm}^{4}
$$

Using the values from above, we calculate the effective moment of inertia $\left(I_{e @ \Delta T}\right)$ using equation (3):

$$
\begin{gathered}
{\left[\frac{85.82}{900.97}\right]^{3} 9,045,456,461} \\
+\left[1-\left[\frac{85.82}{900.97}\right]^{3}\right] 6,363,384,270
\end{gathered}
$$

Therefore,

$$
I_{e @ \Delta T}=6,365,702,225 \mathrm{~mm}^{4}
$$

Finally, the flexural rigidity $(E I)_{\Delta T}$ can be established for the structure at a temperature of $175^{\circ} \mathrm{C}$. Substitution into equation (1) provides:

$$
\begin{gathered}
(E I)_{\Delta T}=E_{c} @ \Delta T \\
I_{e @ \Delta T} \\
(E I)_{\Delta T}=(26,500)(6,365,702,225) \\
(E I)_{\Delta T}=(1.69)\left(10^{14}\right) N-m^{2}
\end{gathered}
$$

Superposition will now be used to determine the deflection. 


$$
\begin{gathered}
\Delta_{T}=-\frac{5 P_{e} e \ell^{2}}{48(E I)_{\Delta T}}+\frac{P_{L} \ell^{3}}{46(E I)_{\Delta T}}+\frac{5\left(W_{D}+W_{L}\right) \ell^{4}}{384(E I)_{\Delta T}} \\
\Delta_{T}=-\frac{(5)(120000)(327)(5500)^{2}}{(48)(1.69)\left(10^{14}\right)} \\
+\frac{(500000)(5500)^{3}}{(46)(1.69)\left(10^{14}\right)} \\
+\frac{(5)(6120)(5.5)^{4}(1000)^{3}}{(384)(1.69)\left(10^{14}\right)} \\
\Delta_{T}=10.40 \mathrm{~mm}
\end{gathered}
$$

The ANSYS model predicted a deflection of $8.52 \mathrm{~mm}$. This $1.87 \mathrm{~mm}$ difference can be attributed to delamination of the FRP tension reinforcement and prestress losses in the structure. In addition, this deflection is within the recommended $\mathrm{ACl}$ deflection range of $\ell / 800$ to $\ell / 525$. In an attempt to provide an indirect reference to the real behavior of the material, a smoldering fire as described in Application of Fire Safety Engineering [28] was chosen to display the internal behavior of the structure in a fire scenario. It was found that their deflection was $8.52 \mathrm{~mm}$. This is in good agreement with our work.

\section{Conclusions and Future Studies}

In this article a basic analytical model is developed using the flexural rigidity of a concrete T-beam reinforced with both prestressed and non-prestressed CFRP reinforcement to study the deflection behavior within the range of practical elevated temperatures. The model is compared with a finite element model of a concrete T-beam reinforced with same reinforcement subjected to practical elevated temperatures. In addition, comparison is also made with an indirect reference to the real behavior of material. It was found that the results of the analytical model correlated reasonably with the finite element model, real material behavior, and were within accepted range of the $\mathrm{ACl}$ specifications.

It may be noted that this work is a basic first step towards cost effective, efficient, and practical consideration in fire safety design of FRPs. There are various prospects of extending the scope of this work. Some of the future areas of study maybe to develop models with different fibers, perform experimental work, and carry out comparative analyses. These may further progress considerations in fire safety design.

\section{Notation}

$A \quad=\quad$ Area of the geometry

$\mathrm{A}_{\mathrm{c}}=$ Area of the gross concrete cross section

$\mathrm{A}_{\text {cfrp }}=\quad$ Area of the total tension CFRP 


\begin{tabular}{|c|c|c|}
\hline $\mathrm{c}_{1}$ & $=$ & Distance of the neutral axis to the top of flange \\
\hline $\mathrm{d}$ & $=$ & Distance to the neutral axis \\
\hline $\mathrm{E}_{\mathrm{c}}$ & $=$ & Modulus of elasticity for the concrete \\
\hline $\mathrm{E}_{C} @ \Delta^{\prime}$ & & Temperature based modulus of elasticity of the concrete \\
\hline $\mathrm{E}_{\text {CFRP }}$ & $@ \Delta \mathrm{T}=$ & Temperature based modulus of elasticity of the CFRP \\
\hline $\mathrm{E}_{\mathrm{f}}$ & $=$ & Modulus of elasticity for the fiber \\
\hline $\mathrm{E}_{\mathrm{m}}$ & $=$ & Modulus of elasticity for the matrix \\
\hline $\mathrm{E}_{\mathrm{m} @ \Delta}$ & & Temperature based modulus of the matrix \\
\hline$(\mathrm{EI})_{\Delta^{\prime}}$ & & Temperature based effective flexural rigidity for the structural system \\
\hline $\mathrm{e}$ & $=$ & Eccentricity \\
\hline $\mathrm{f}_{1}$ & $=$ & Compressive stress in the top extreme concrete fiber \\
\hline $\mathrm{f}_{\mathrm{c}}^{\prime}$ & $=$ & Compressive strength of the concrete \\
\hline $\mathrm{f}_{\mathrm{r}}$ & $=$ & Modulus of rupture \\
\hline $\mathrm{I}_{\mathrm{cr}}$ & $=$ & Cracked moment of inertia \\
\hline $\mathrm{I}_{\mathrm{e}}$ & $=$ & Effective moment of inertia \\
\hline $\mathrm{I}_{\mathrm{g}}$ & $=$ & Gross area moment of inertia \\
\hline $\mathrm{I}_{\mathrm{o}}$ & $=$ & Moment of inertia about geometric centroid \\
\hline$\left(\mathrm{I}_{\mathrm{cr}}\right)_{\Delta}$ & & Temperature based cracked cross section of the moment of inertia \\
\hline $\mathrm{I}_{\mathrm{e} @ \Delta \mathrm{T}}$ & $=$ & Temperature based effective moment of inertia \\
\hline$\ell$ & $=$ & Length of the structure \\
\hline $\mathrm{M}_{\mathrm{a}}$ & $=$ & Action moment \\
\hline $\mathrm{M}_{\mathrm{T}}$ & $=$ & Total service Moment \\
\hline$\left(\mathrm{M}_{\mathrm{cr}}\right)$ & & Temperature based cracking moment \\
\hline $\mathrm{P}_{\mathrm{e}}$ & $=$ & Effective prestressing force \\
\hline $\mathrm{P}_{\mathrm{L}}$ & $=$ & Live load force \\
\hline r & $=$ & Reduction factor of the concrete modulus of elasticity \\
\hline$r_{g}$ & $=$ & Radius of gyration \\
\hline$R 1$ & $=$ & Reaction force at the left support \\
\hline$R 2$ & $=$ & Reaction force at the right support \\
\hline$S_{1}$ & $=$ & Top section modulus \\
\hline $\mathrm{T}_{\mathrm{g}}$ & $=$ & Glass transition temperature \\
\hline$V_{f}$ & $=$ & Volume fraction of the fiber \\
\hline $\mathrm{V}_{\mathrm{m}}$ & $=$ & Volume fraction of the fiber \\
\hline $\mathrm{W}_{\mathrm{D}}$ & $=$ & Uniform distributed dead load \\
\hline $\mathrm{W}_{\mathrm{L}}$ & $=$ & Uniform distributed live load \\
\hline$x$ & $=$ & Distance to the neutral axis from the bottom of the compression flange \\
\hline $\mathrm{y}_{\mathrm{t}}$ & $=$ & Depth of the tension section of the cross section \\
\hline
\end{tabular}

\section{Greek letters}

$\Delta_{\mathrm{T}} \quad=\quad$ Deflection at elevated temperature 
$\eta_{\text {cfrp@sT }}=\quad$ Temperature based modular ratio

$v \quad=$ Poisson's ratio

\section{Author Contributions}

Zachary Scott Dean (graduate student): Conducted all the FE models, data and results processing and writing the paper content; Others: Contributed equally to the work in various ways.

\section{Competing Interests}

The authors have declared that no competing interests exist.

\section{References}

1. Faruqi M, Khan MS. Deflection behavior of a prestressed concrete beam reinforced with carbon fibers at elevated temperatures. Front Struct Civ Eng. 2019; 13: 81-91.

2. Benichou N, Kodur V, Bisby L, Chowdhury E, Green M. Results of fire resistance experiments on FRPstrengthened reinforced concrete columns. Report No. 2. Ottawa: Institute for Research in Construction; 2007; NRC-IRC-18714

3. Bisby LA, Green MF, Kodur VK. Response to fire of concrete structures that incorporate FRP. Prog Struct Eng Mater. 2005; 7: 136-149.

4. Hawileh RA, Naser M, Zaidan W, Rasheed, HA. Modeling of insulated CFRP-strengthened reinforced concrete T-beam exposed to fire. Eng Struct. 2009; 31: 3072-3079.

5. Naser M, Abu-Lebdeh G, Hawileh R. Analysis of RC T-beams strengthened with CFRP plates under fire loading using ANN. Constr Build Mater. 2012; 37: 301-309.

6. Hawileh RA, Naser M, Rasheed HA. Thermal-stress finite element analysis of CFRP strengthened concrete beam exposed to top surface fire. Mech Adv Mater Struct. 2011; 18: 172-180.

7. Zou PX. Theoretical study on short-term and long-term deflections of fiber reinforced polymer prestressed concrete beams. J Compos Constr. 2003; 7: 285-291.

8. Agarwal BD, Broutman $\amalg$, Chandrashekhara K. Analysis and performance of fiber composites. 3rd ed. New York: John Wiley \& Sons; 2006.

9. Kodur V, Agarawal A. A numerical approach for evaluating residual capacity of fire damaged concrete members. Rev ALCONPAT. 2020; 10: 230-242.

10. Eurocode 2: Design of concrete structures-Part 1-2: General rules-Structural fire design. Brussels: European Concrete Platform; 2004. EN 1992-1-2.

11. Phan LT. Fire performance of high-strength concrete: A report of the state of the art, technical report. Gaithersburg: National Institute of Standards and Technology; 1996.

12. Kodur VK, Phan L. Factors governing the fire performance of high strength concrete systems. Fire Saf J. 2007; 42: 482-488.

13. Castillo C, Durrani AJ. Effect of transient high temperature on high-strength concrete. ACI Mater J. 1990; 87: 47-53.

14. Bosze EJ, Alawar A, Bertschger O, Tsai YI, Nutt SR. High-temperature strength and storage modulus 
in unidirectional hybrid composites. Compos Sci Technol. 2006; 66: 1963-1969.

15. Samaniego E, Oliver J, Huespe AE. Contributions to the continuum modelling of strong discontinuities on two-dimensional solids. Catalunya, Spain: Universitat Politècnica de Catalunya; 2003.

16. Belytschko T, Black T. Elastic crack growth in finite elements with minimal remeshing. Int J Numer Methods Eng. 1999; 45: 601-620.

17. Belytschko T, Moës N, Usui S, Parimi C. Arbitrary discontinuities in finite elements. Int J Numer Methods Eng. 2001; 50: 993-1013.

18. Wells GN, Sluys $\amalg$. A new method for modelling cohesive cracks using finite element. Int J Numer Methods Eng. 2001; 50: 2667-2682.

19. Xu XP, Needleman A. Numerical simulations of dynamic crack growth along an Interface. Int J Fract. 1996; 74: 289-324.

20. Belytschko T, Lu YY, Gu L. Element-free Galerkin methods. Int J Numer Methods Eng. 1994; 37: 229256.

21. Belytschko T, Lu YY, Gu L, Tabbara M. Element-free galerkin methods for static and dynamic fracture. Int J Solids Struct. 1995; 32: 2547-2570.

22. Rabczuk T, Belytschko T. Application of particle methods to static fracture of reinforced concrete structures. Int J Fract. 2006; 137: 19-49.

23. Rabczuk T, Zi G, Bordas S, Nguyen-Xuan H. A geometrically non-linear three-dimensional cohesive crack method for reinforced concrete structures. Eng Fract Mech. 2008; 75: 4740-4758.

24. Rabczuk T, Akkermann J, Eibl J. A numerical model for reinforced concrete structures. Int J Solids Struct. 2005; 42: 1327-1354

25. ASCE, ASCE 7-10. Minimum design loads for buildings and other structures. Reston: American Society of Civil Engineers; 2013

26. Park R, Paulay T. Reinforced concrete structures. New York: John Wiley \& Sons; 1975.

27. $\mathrm{ACl}$ Committee. Building code requirements for structural concrete $(\mathrm{ACl} 318)$ and commentary $(\mathrm{ACl}$ 318R). Farmington Hills: American Concrete Institute; 2011.

28. PD 7974-1:2003 Application of fire safety engineering principles to the design of buildings. Initiation and development of fire within the enclosure of origin (Sub-system 1). London, UK: British Standards Institution; 2003. 


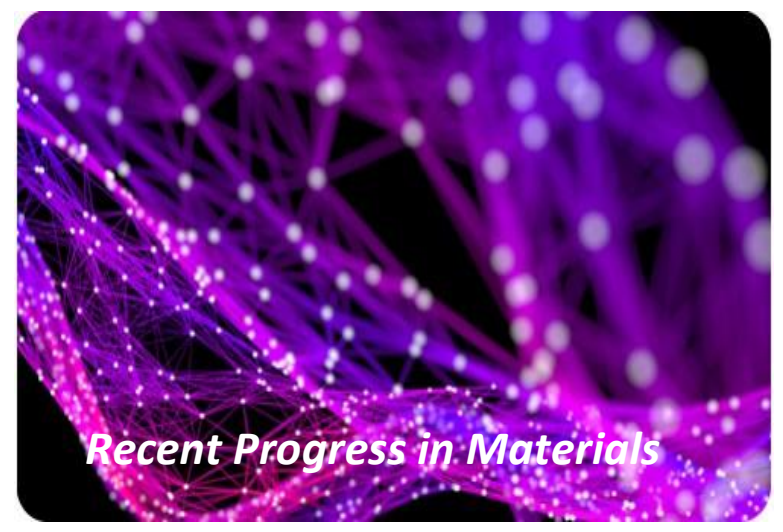

Enjoy Recent Progress in Materials by:

1. Submitting a manuscript

2. Joining in volunteer reviewer bank

3. Joining Editorial Board

4. Guest editing a special issue

For more details, please visit:

http://www.lidsen.com/journals/rpm 